\title{
Learning or Leaving? Individual and Environmental Factors Related to Job Satisfaction and Turnover Intention
}

\author{
Ilmari J. A. Puhakka ${ }^{1}$ (D) Petri Nokelainen ${ }^{1}$ (D) Laura Pylväs $^{2}$ (D)
}

Received: 10 September 2020 / Accepted: 1 July 2021 / Published online: 10 July 2021

(c) The Author(s) 2021

\begin{abstract}
In addition to well-being, workplace learning has gained increasing interest in supporting employee and organizational development and success. Focusing on specific factors affecting workplace learning and well-being, this study examines the links between individual factors (basic psychological need satisfaction) and environmental factors (expansiveness of the workplace as a learning environment), job satisfaction, and turnover intention. Survey data were collected from the employees $(N$ $=153$ ) of two Finnish engineering companies from 2018 to 2019. The data were analyzed with correlation analysis and structural equation modeling (observed and latent variable path analysis). Results show that a more expansive workplace learning environment is associated with higher satisfaction of basic psychological needs. High levels of autonomy and competence need satisfaction, versatile work, promotion of learning, and acknowledgment of skills are positively associated with job satisfaction. Higher levels of autonomy and non-routine work tasks are associated with lower turnover intention. The results indicate that turnover intention is not necessarily associated with only negative conditions or perceptions, as high levels of competence and participation and understanding of the workplace are positively associated with turnover intention. The findings provide information about workplace factors that are relevant to improving employees' workplace learning and well-being. The results also highlight the ambiguous nature of turnover intention.
\end{abstract}

Keywords Workplace learning environment - Basic psychological need satisfaction · Job satisfaction · Turnover intention

Ilmari J. A. Puhakka

ilmari.puhakka@tuni.fi

1 Faculty of Education and Culture, Tampere University, 33014 Tampere, Finland

2 Faculty of Educational Sciences, University of Helsinki, Siltavuorenpenger 1B, Psychologicum, P.O. Box 9, 00014 Helsinki, Finland 


\section{Introduction}

There is a longstanding consensus among researchers that employee well-being affects job attitudes relevant to employees' professional development and organizational success. In addition to research on employee well-being, workplace learning research has emerged in recent decades as a means of providing information not only on employee and organizational development but also on how to answer today's societal and environmental challenges (Hager, 2011; Tynjälä, 2013).

Research on employee job attitudes has a long tradition in organizational psychology (Judge \& Kammeyer-Mueller, 2012). This tradition stems from results pointing to the association between job attitudes and organizational behaviors and performance. Job attitudes can also contribute to general well-being (see Sessa \& Bowling, 2020). Two highly researched job attitudes are job satisfaction (JS) and turnover intention (TI). JS is often regarded as the most important employee attitude (Saari \& Judge, 2004), while employee retention and turnover have been highly acknowledged issues in organizational research over the last few decades (Rubenstein et al., 2018). Job satisfaction is strongly associated with employee subjective well-being (e.g., Bowling et al., 2010) and job performance (Judge et al., 2001), while individual and collective turnover can cause numerous negative consequences, including increased costs, reduced financial performance, and turnover contagion (Hom et al., 2017). During the last decade, concerns about retention rates of STEM (science, technology, engineering, and mathematics) professionals have been raised in the US (Iammartino et al., 2016).

Aside from JS, a plethora of happiness-related constructs have been used in workplace research (e.g., intrinsic motivation), illustrating the interest in studying employee well-being at work (Fisher, 2010). In line with the growing evidence of the influence of emotions and affect on job attitudes and behavior, one related concept that is increasingly being studied in the work context is satisfaction of three basic psychological needs: autonomy, competence, and relatedness (Deci \& Ryan, 2000). Studies have revealed the association between this basic psychological need satisfaction (BPNS) and job attitudes and behaviors, as well as the importance of satisfying basic psychological needs, especially autonomy, in maintaining and improving employee well-being (see Van den Broeck et al., 2016). BPNS is also important in supporting motivation towards learning (e.g., Roca \& Gagné, 2008).

Environmental factors of the workplace have been included in research on workplace learning alongside individual factors, leading to notions of workplaces as learning environments with many social, personal, and economic purposes (Billett et al., 2008). Research has shown that different characteristics of work and workplace learning environment, such as collegial feedback (Doornbos et al., 2008), task or skill variety (Coetzer et al., 2017), and access to knowledge (Fuller \& Unwin, 2004), can enhance workplace learning or perceived learning potential (Rausch, 2013). One way to look at these characteristics and their contribution to workplace learning is through expansive-restrictive framework (Fuller \& Unwin, 2004), where expansive features of the workplace as 
a learning environment (WLE) lead to a richer learning environment. These characteristics or affordances are linked to informal and non-formal workplace learning (Eraut, 2004; Tynjälä, 2008) by providing employees with positive or negative experiences of support for professional development in their workplace environment (Billett \& Henderson, 2011; Fuller \& Unwin, 2010; Pekrun $\&$ Perry, 2014). While these environmental or structural factors determine the available learning opportunities (or learning potential; Ellström, 2001) afforded by the workplace (Billett, 2001), various subjective factors influence the way these environmental conditions are experienced (Ellström, 2011). Important for employees to utilize these learning opportunities are not only the capabilities to identify the affordances, but also individual factors such as motivation. Workplace learning can thus be seen as a multidirectional interplay of characteristics of WLE and individual factors.

In the last few decades, there has been a growing interest in researching factors that enhance or hinder workplace learning and professional development (Hager, 2011). This is particularly important in the STEM fields due to its contributions to the economy and answering contemporary challenges. Learning and well-being are intricately connected in the workplace, however, complex analysis connecting factors of learning and well-being to job attitudes is rare in literature. For example, while the relationships of basic psychological need satisfaction and learning opportunities to job satisfaction and turnover intention have been studied separately (e.g., Felstead et al., 2015; Van den Broeck et al., 2016), there is a lack of research providing a more complex analysis of the intercorrelations between these factors. Thus, this study aims to raise both practical and theoretical notions by examining connections of factors influencing learning and well-being in work while increasing understanding of workforce (especially STEM) retention and development. We address these issues with the following research questions: (RQ1) Is employees' BPNS in the workplace associated with JS and TI?; (RQ2) Is the expansiveness of employees' WLE associated with JS and TI?; (RQ3) Are the employees' level of BPNS and the expansiveness of WLE, when examined together, related to JS and TI, and which dimensions of BPNS and WLE have the strongest relationships with JS and TI? In this study, the 3-P model of workplace learning (Tynjälä, 2013) is applied to illustrate the different levels of factors connected to workplace learning in a sociocultural environment. The following section introduces the 3-P model and how it is used to frame the study constructs.

\section{Modeling Workplace Learning}

The 3-P model of workplace learning (Tynjälä, 2013) is a useful instrument for illustrating the different levels of factors connected to workplace learning. ${ }^{1}$ The

\footnotetext{
1 The 3-P model has a long history of adaptations beginning from Dunkin and Biddle's (1974) "model for the study of classroom teaching" (p. 38), which was based on terminology of Presage, Process, and Product by Mitzel (1960). Later, Biggs (1993) modified the model as a 3P Learning model. Biggs' model was further adapted by Tynjälä (2013) with the focus on workplace learning.
} 


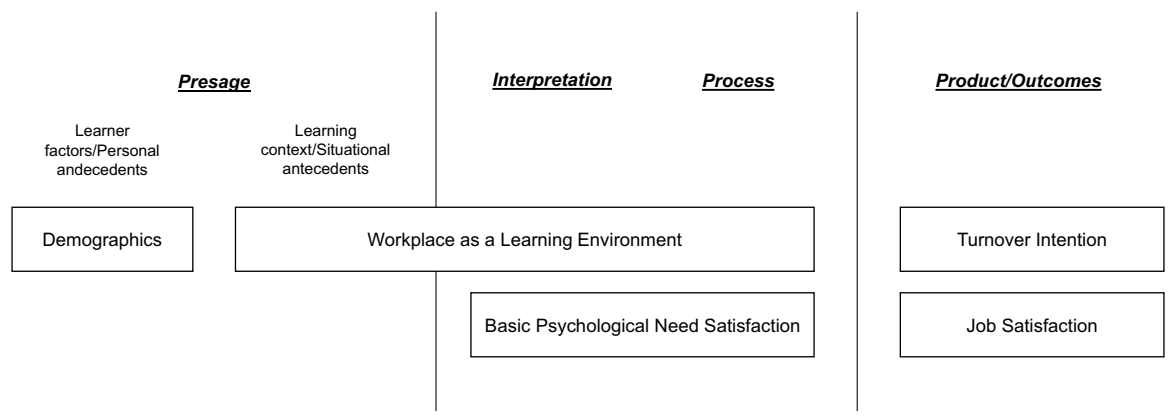

Fig. 1 Illustration of the theoretical constructs of this study in the context of 3-P model of workplace learning (Tynjälä, 2013) and the model of informal learning behaviors (Cerasoli et al., 2018)

model describes three basic components of learning in a sociocultural environment: presage, process, and product. The presage component includes learner factors (e.g., knowledge and experience) and the learning context (e.g., organizational structure), the process component includes learning activities (e.g., participating in networks), and the product component consists of learning outcomes (e.g., personal development). Additionally, there is an interpretation factor between the presage and process components that includes the interpretation of presage factors. Sociocultural environment represents the wider context where workplace learning takes place by defining the possibilities and constraints of workplace learning. This includes, according to Tynjälä's (2013) model, technical-organizational environment, organizational learning, and communities of practice. As professional development results from the interplay of subjective experiences and perceptions of the environment (Harteis \& Billett, 2008), professional development and workplace learning are relatively analogous in the model. Following this interpretation of professional development, JS and TI can be seen as different ends of a continuum.

To illustrate our theoretical constructs (Figure 1), we use the aforementioned 3-P model of workplace learning alongside with the model of informal learning behaviors (Cerasoli et al., 2018) that brings in personal and situational antecedents and outcomes (including job satisfaction). Demographics are situated in the presage component as part of learner factors (or personal antecedents). Due to the interplay between structural characteristics and individual processes (e.g., Ellström, 2011), we situate WLE in both presage (learning context or situational antecedents) and process components in the 3-P model. WLE is differentiated from sociocultural environment in terms of specificity: WLE includes specific characteristics of workplace learning context (e.g., task variety), while sociocultural environment refers to wider context (see Tynjälä, 2013). BPNS is part of both the interpretation and process components: the perception of need satisfaction is influenced by learner factors (e.g., work experience) and learning context (e.g., WLE) but is also an active component in producing intrinsic motivation and job attitudes. JS and TI are situated in the product component because they are influenced by perceptions of WLE and BPNS. Finally, JS and TI influence WLE and BPNS to form a configuration of factors contributing to workplace learning. 
These key factors were chosen due to three main reasons. First, all of these factors are connected to workplace learning and well-being in literature (these connections are described in detail in the following sections). Second, even though separate comparisons between these factors are present in literature, a complex analysis of these individual and environmental factors is missing. Finally, validated questionnaires exist to examine these factors with possibilities to raise recommendations for practice. In the next sections, we define the key concepts, establish their connections to workplace learning and well-being, and present our hypotheses reflecting the previous literature.

\section{Job Satisfaction}

Job satisfaction (JS) can be defined as how people feel about their jobs in general or about the different facets of their job (Spector, 1997). It can be also defined as a positive emotional state arising from one's job or job experiences (Locke, 1976). JS has been actively researched for over a century from various viewpoints (see Judge et al., 2017); the current emphasis is on the affective aspect of JS. While affect has long been included in the definitions of JS, the developed measuring instruments have often neglected this aspect (Brief, 1998). The link between JS and job performance was highly debated in the past (Judge et al., 2001). Studies have since established links between JS and workplace learning (Rowden \& Conine, 2005), informal learning (Berg \& Chyung, 2008), subjective well-being (Bowling et al., 2010), and organizational learning capability (Chiva \& Alegre, 2008).

\section{Turnover Intention}

Specific definitions of turnover intention (TI) are scarce, with some exceptions, notably by Tett and Meyer (1993, p. 262), who defined TI as “.... conscious and deliberate willfulness to leave the organization." Researchers have argued that TI can be used as a proxy for actual turnover (e.g., Tett \& Meyer, 1993), because of the relative strong association between TI and actual turnover. Studying TI is thus important not only because it can enhance understanding of actual turnover but also because it can help identify ways to influence intentions. Models explaining TI have focused on organizational resources and demands (e.g., job resources-demands model; Bakker \& Demerouti, 2007) and organizational learning culture (e.g., Egan et al., 2004). In the latter model, JS has a mediating role between TI and learning culture. Turnover was linked to JS as early as over 50 years ago (see Hom et al., 2017), and a negative association between JS and TI was later established (Tett \& Meyer, 1993).

\section{Basic Psychological Need Satisfaction}

Self-determination theory (SDT) is a theory of human motivation and personality that is used to examine conditions that enhance or hinder human psychological growth and well-being (Ryan \& Deci, 2017). SDT describes intrinsic motivation 
(doing an activity for the satisfaction of the activity itself), extrinsic motivation (doing an activity to reach a separate outcome), and amotivation (lack of motivation) (Ryan \& Deci, 2000). According to SDT, basic psychological need satisfaction (BPNS) is essential to achieving the benefits of intrinsic motivation (Ryan \& Deci, 2000). A subtheory of SDT, basic psychological needs theory, posits that psychological wellness and functioning are affected by the satisfaction or frustration of three basic psychological needs: the need for autonomy (BPNS_A), the need for competence (BPNS_C), and the need for relatedness (BPNS_R) (Deci \& Ryan, 1985, 2000; Ryan \& Deci, 2000). Research has provided substantive support for the importance of BPNS in well-being indicators (e.g., life satisfaction; Chen et al., 2015). Basic psychological needs seem to better predict positive aspects of well-being and positive rather than negative forms of motivation (Van den Broeck et al., 2016). Each need facilitates the satisfaction of the other needs; thus, they are positively related to one another (Ryan \& Deci, 2017). Special focus is often placed on autonomy support for its critical role in enabling the satisfaction of other needs in most settings.

In the work context, research has shown that working conditions with plenty of job resources (e.g., task autonomy, supervisory support, skill utilization, and positive feedback) lead to better BPNS, whereas conditions with increased job demands (e.g., workload, emotional demands, physical demands, and work-home interference) could impede need satisfaction (Van den Broeck et al., 2008). Positive associations between intrinsic motivation and JS, as well as between intrinsic motivation and organizational commitment, have been observed (Ryu \& Moon, 2019). BPNS is also associated with indicators of job attitudes, well-being, and motivation at work (see Van den Broeck et al., 2016). Since BPNS is essential in supporting intrinsic and autonomous motivation, effective learning and development in work is influenced by BPNS (Roca \& Gagné, 2008; Ryan \& Deci, 2017)

Previous research has established a strong positive correlation between the dimensions of BPNS (e.g., Chen et al., 2015; Martela et al., 2018; Van den Broeck et al., 2016). Studying over 1,000 students from four nations, Chen et al. (2015) found strong associations between the psychological needs, especially between BPNS_A and BPNS_C $(r=.61)$. Although there are fewer studies of BPNS in the workplace context, the results are similar (autonomy-competence: $r$ $=.44$, autonomy-relatedness: $r=.47$, competence-relatedness: $r=.35$; Van den Broeck et al., 2016). In the workplace context, research has revealed connections between BPNS and job attitudes (e.g., JS and TI). Results of a meta-analysis by Van den Broeck et al. (2016) showed that BPNS was positively associated with JS (autonomy-JS: $r=.54$, competence-JS: $r=.40$, relatedness-JS: $r=.42$ ) and negatively associated with TI (autonomy-TI: $r=-.31$, competence-TI: $r=-.05$, relatedness-TI: $r=-.21$ ). Schultz et al. (2015) found that BPNS had a negative relationship with TI $(r=-.49)$. Based on the aforementioned studies, we hypothesize the following:

H1: The dimensions of BPNS are positively associated with each other.

$\mathrm{H} 2$ : The dimensions of BPNS are positively related to JS and negatively related to TI. 


\section{Expansive Workplace Learning Environments}

The characteristics of workplace learning environments have been conceptualized in different ways (e.g., Clarke, 2005; Ellström, 2011; Fuller \& Unwin, 2004). The expansive-restrictive framework by Fuller and Unwin $(2003,2004)$ attempts to capture the factors contributing to the creation of learning environments and workforce development. In this framework, an approach characterized by expansive rather than restrictive features leads to a richer learning environment (Fuller \& Unwin, 2004). An expansive approach is thus expected to increase the quality and range of opportunities for participation in the workplace. Expansive learning is aimed at employees and learning in contrast to the organizational transformation emphasized by other researchers (e.g., Engeström, 2001). According to the sociocultural approach, engagement in activities and participation in the workplace (as a "community of practice") are viewed as key sources of learning through work (e.g., Billett, 2001; Lave \& Wenger, 1991).

Based on the theory of expansive learning environments (Fuller \& Unwin, 2004), James and Holmes (2012) developed a questionnaire, Workplace as a Learning Environment Survey (WLES), to examine the expansiveness of the workplace as a learning environment (WLE). Other instruments have also been used to measure workplace learning environments. Tannenbaum (1997) developed a survey to examine organizational aspects that influence continuous learning, while Felstead et al. (2015) used a six-question survey to measure which jobs offer more learning opportunities. Learning opportunities, sometimes used as a proxy for workplace learning (e.g., Van Ruysseveldt et al., 2011), are related to autonomy (Schaufeli et al., 2009; Van Ruysseveldt et al., 2011), which links BPNS to workplace learning environments.

Studies have linked JS to learning environments through organizational learning capabilities (e.g., Chiva \& Alegre, 2008) and learning opportunities (Felstead et al., 2015). The dimensions of learning organization (Marsick \& Watkins, 2003) were shown to have a negative relationship with TI (Islam et al., 2015). Govaerts et al. (2011) reported that an appreciative learning and working climate (i.e., one that provides learning opportunities and a feeling of being appreciated by supervisors and colleagues) was a good predictor of employees' intention to stay.

An earlier study of 305 Finnish apprentices using WLES (Nokelainen et al., 2018) showed medium to strong positive correlations (ranging from .31 to .71) between the seven WLE dimensions (see Research instruments for details). The strongest associations were between WLE1 (Participation and understanding of the workplace) and WLE2 (Task performance) $(r=.71)$, WLE2 (Task performance) and WLE4 (Judgement, decision-making, problem-solving, and reflection) $(r=.60)$, and WLE3 (Access to resources to help learning) and WLE5 (Experience and task transition) $(r=.60)$. Although earlier studies using WLES (James \& Holmes, 2012; Nokelainen et al., 2018) involved younger participants (apprentices) than those in the present study (see Participants for details), we expect to find positive associations between the seven WLE dimensions. While WLES has not been used in research on JS and TI, the expansiveness of job learning experiences has been studied in connection with JS, and studies have combined closely associated concepts (e.g., learning organization, appreciative 
learning, and working climate) with TI. Felstead et al. (2015) found that jobs that offered more learning opportunities (i.e., more expansive jobs) were associated with higher JS, whereas more restrictive jobs were associated with lower JS. With regard to TI, Govaerts et al. (2011) found that an appreciative learning and working climate was negatively related to the intention to leave. In addition, Islam et al. (2015) found that a functioning organizational learning culture was negatively related to TI. Based on the aforementioned research, we hypothesize the following:

H3: The dimensions of WLE are positively associated with each other.

H4: The dimensions of WLE are positively related to JS and negatively related to TI.

To our knowledge, BPNS and the expansiveness of WLE have not been examined together in research. However, some studies have found positive associations between task variety (similar to WLE2; see Appendix) and BPNS_C (Doornbos et al., 2008). Van Ruysseveldt et al. (2011) also found that autonomy and task variety promoted learning opportunities. Due to the similarities between the measures of certain dimensions (e.g., BPNS_A and WLE4; see Appendix), we hypothesize:

H5: The dimensions of BPNS are positively associated with the dimensions of WLE.

Based on the results of a meta-analysis by Tett and Meyer (1993; JS-TI: $r=-.58$ ) and a study by Martin and Roodt (2008; JS-TI: $r=-.69$ ), we expect to find a negative association between JS and TI, and thus hypothesize:

H6: JS and TI are negatively associated with each other.

Following the previous hypotheses (H1, H2, H3, H4, and H5), we expect that, in the model (including BPNS, WLE, JS, and TI), BPNS and the expansiveness of WLE will be positively related to JS and negatively related to TI after controlling for demographic factors. Using path analysis, we also aim to further explore the associations the BPNS and WLE dimensions have with JS and TI. Our final hypotheses are as follows:

H7: Satisfaction of BPN and the expansiveness of WLE are positively related to JS and negatively related to TI.

H8: There are statistically significant relationships between particular dimensions of BPNS and JS, BPNS and TI, WLE and JS, and WLE and TI.

\section{Methods}

\section{Participants}

Study participants $(N=153)$ were employees of two companies operating in the Finnish engineering sector. Participants were asked about the following demographic 
Table 1 Demographic information

\begin{tabular}{llll}
\hline & Company A & Company B & Total \\
\hline Sample size & 105 & 48 & 153 \\
Gender, $n$ (\%) & & & \\
$\quad$ Woman & $48(45.7)$ & $6(12.8)$ & $54(35.5)$ \\
Man & $55(52.4)$ & $40(85.1)$ & $95(62.5)$ \\
Prefer not to answer & $2(1.9)$ & $1(2.1)$ & $3(2.0)$ \\
Age (years), $M(S D)$ & $37.8(9.692)$ & $37.5(7.053)$ & $37.7(8.920)$ \\
Total work experience (years), $M(S D)$ & $14.9(9.343)$ & $12.4(7.008)$ & $14.1(8.724)$ \\
Title, $n$ (\%) & & & \\
Support personnel (e.g., IT support, security) & $3(2.9)$ & $1(2.1)$ & $4(2.7)$ \\
Expert (beginner, intermediate, senior levels) & $62(59.1)$ & $39(81.3)$ & $101(66.9)$ \\
Manager (first, middle, senior levels) & $36(34.3)$ & $5(10.4)$ & $41(27.2)$ \\
Other (e.g., trainee) & $2(1.9)$ & $3(6.3)$ & $5(3.3)$ \\
Education (highest degree), $n$ (\%) & & & \\
Basic level (e.g., primary school) & $0(0.0)$ & $0(0.0)$ & $0(0.0)$ \\
Upper secondary level (e.g., high school) & $6(5.7)$ & $3(6.4)$ & $9(5.9)$ \\
Lowest level tertiary (e.g., technician engineer) & $1(1.0)$ & $2(4.3)$ & $3(2.0)$ \\
Lower-degree level tertiary (e.g., polytechnic degree) & $39(37.1)$ & $10(21.3)$ & $49(32.2)$ \\
Higher-degree level tertiary (e.g., master's degree) & $56(53.3)$ & $29(61.7)$ & $85(55.9)$ \\
Doctorate level (licentiate or doctorate degree) & $3(2.9)$ & $3(6.4)$ & $6(4.0)$ \\
\hline
\end{tabular}

$n=$ sample size; $M=$ mean; $S D=$ standard deviation

information at the beginning of the survey: participant's organization (Company A: $n=105$, Company B: $n=48)$, gender $(n=149,36.2 \%$ female and $63.8 \%$ male), age $(n=152$, range $=19-61$ years, $M=37.7, S D=8.920)$, total work experience $(n$ $=148$, range $=1-40$ years, $M=14.1, S D=8.724)$, current work title, and highest obtained degree of education. Table 1 describes the study participants' demographic information. Company A is a large international Finnish consulting company and company B is a large international Finnish software development company, both in the male-dominated engineering sector. The companies are representative of the Finnish engineering sector with respect to the number of personnel (200-2,200 employees) and finances (2015 revenues between EUR 26 and 135 million).

\section{Procedure}

Research data were collected via an online survey during 2018-2019. The survey included questions about demographic information and the four questionnaires (described in detail further on). After receiving approval from the management of both companies, the survey link was shared with the employees. Company A shared the survey link with the workers of the local office, while company B distributed the survey link nationally. Response rates were relatively low (company A: $28 \%$, 
company B: 11\%), however, the distributions of gender groups, age, and job titles reflected adequately the two companies.

\section{Research Instruments}

Job Satisfaction We used a three-item subscale with a 5-point self-rating scale (1 = totally disagree, $5=$ totally agree) from the Michigan Organizational Assessment Questionnaire Job Satisfaction Subscale (MOAQ-JSS; see Bowling \& Hammond, 2008). The MOAQ-JSS is a shortened version of the seven-item Michigan Organizational Assessment Questionnaire by Cammann et al. (1979). The three items loading on one factor are as follows: 1) "All in all, I am satisfied with my job," 2) "In general, I don't like my job," and 3) "In general, I like working here." The second item was reverse coded before the average MOAQ-JSS score was calculated ( $\alpha=.820, M$ $=4.1, S D=0.691)$. Correlations between these items were all positive and between .51 and .61 . The appendix presents the item level statistics of the three MOAQ-JSS items.

Turnover Intention The Turnover Intention Scale (TIS; see Bothma \& Roodt, 2013) has one factor measured with four items on a 5-point self-rating scale ( 1 = never, 5 = always). The participants were asked to think back on the past six months and respond to the following items: 1) "How often are you frustrated when not given the opportunity at work to achieve your personal work-related goals?" 2) "How often are your personal values at work compromised?" 3) "How often do you dream about getting another job that will better suit your personal needs?" and 4) "How often do you look forward to another day at work?" The fourth item was reverse coded before the average TIS score was calculated $(\alpha=.779, M=2.6, S D=0.785)$. Correlations between these items were all positive and between .33 and .54 . The appendix presents the item level statistics of the four TIS items.

Basic Psychological Need Satisfaction The original Basic Psychological Needs Satisfaction and Frustration (BPNSF) survey (Schultz et al., 2015) contains 24 selfrating items on six factors that measure both satisfaction and frustration components for autonomy, competence, and relatedness. We used 12 items of the instrument that were designed to measure the satisfaction component (BPNS). Sample items are as follows: "At work, I feel a sense of choice and freedom in the things I undertake" (autonomy satisfaction or BPNS_A), "I feel confident that I can do things well on my job" (competence satisfaction or BPNS_C), and "I feel that the people I care at work about also care about me" (relatedness satisfaction or BPNS_R). Items were rated on a 5 -point scale $(1=$ totally disagree, $5=$ totally agree $)$. The internal consistency (Cronbach's alpha; Cronbach, 1951) of the three components (Table 2) proved to be satisfactory (see Lance et al., 2006).

The participants responded to the survey items on the three BPNS dimensions using the full response scale. The three BPNS dimensions had relatively high values (Table 2). The analysis of skewness $\left(\mu_{3}\right)$ shows that the tail of the distribution on all three dimensions is on the left side (skewness values are negative), indicating 
participants' tendency to use more positive (e.g., $5=$ totally agree) response values. The kurtosis $\left(\mu_{4}\right)$ values for the three BPNS dimensions are below 3 , indicating a platykurtic distribution, which has fewer outliers than a normal distribution. The appendix presents the item level statistics of the 12 BPNS items.

Expansiveness of the Workplace as a Learning Environment The WLES (James \& Holmes, 2012) contains 21 items rated on a 5-point scale $(1=$ totally disagree, 5 = totally agree). The survey addresses seven main areas that are related to expansive learning environments (sample statements are in parentheses): participation and understanding of the workplace (WLE1; "I understand the goals and aims of the workplace"); task performance (WLE2; "I use a range of skills in my work"); access to resources to help learning (WLE3; "I have a mentor/coach at work"); judgment, decision making, problem solving, and reflection (WLE4; "I am allowed to make decisions of my own in my job); experience and task transition (WLE5; "I am given time to work through tasks to develop my skills and knowledge"); recognition as an expert (WLE6; "My colleagues or superior[s] recognize me as an expert of my field"); and organizational development (WLE7; "The business-related goals of the workplace are in line with my own goals to develop my professional skills"). In this study, we rephrased some items (as the original survey was developed for studies in the field of apprenticeship training) and reduced them to 18 based on the findings of Nokelainen et al. (2018), who used the original version of the instrument. The internal consistency values of the seven WLE components ranged from .588 to .794 (Table 2). The low alpha values reflect the low number of items per factor (2-4) and the inherent multidimensionality of WLE4 $(\alpha=.588)$ and WLE5 $(\alpha=.623)$. We suspect that the multidimensionality weighs more in this case, as the seventh factor focuses solely on the match between the organization's and workers' goals, with only two items producing an alpha value of .794.

The participants used the full response scale for four WLE dimensions (WLE2, WLE5, WLE6, and WLE7). Their responses on the other three dimensions (WLE1, WLE3, and WLE4) tended to be positive (range =1.3-5.0). Six of the WLE dimensions had relatively high central tendency values, while only WLE5 had moderate values (Table 2). The skewness analysis shows that the tail of the distribution on all seven dimensions is on the left side $\left(\mu_{3}<0\right)$, indicating participants' tendency toward positive (e.g., $5=$ totally agree) responses. The kurtosis values of six WLE dimensions are below 3, indicating a platykurtic distribution. However, the probability distribution of WLE2 is leptokurtic, which means that it has more outliers than the normal distribution. The appendix presents the item level statistics of the 21 WLES items.

\section{Statistical Analyses}

The examination of missing observations in the data revealed only few (1-5) missing cases per variable. Casewise omission was used in the analyses instead of imputation of missing data resulting in the minimum sample size of 143 with the path 


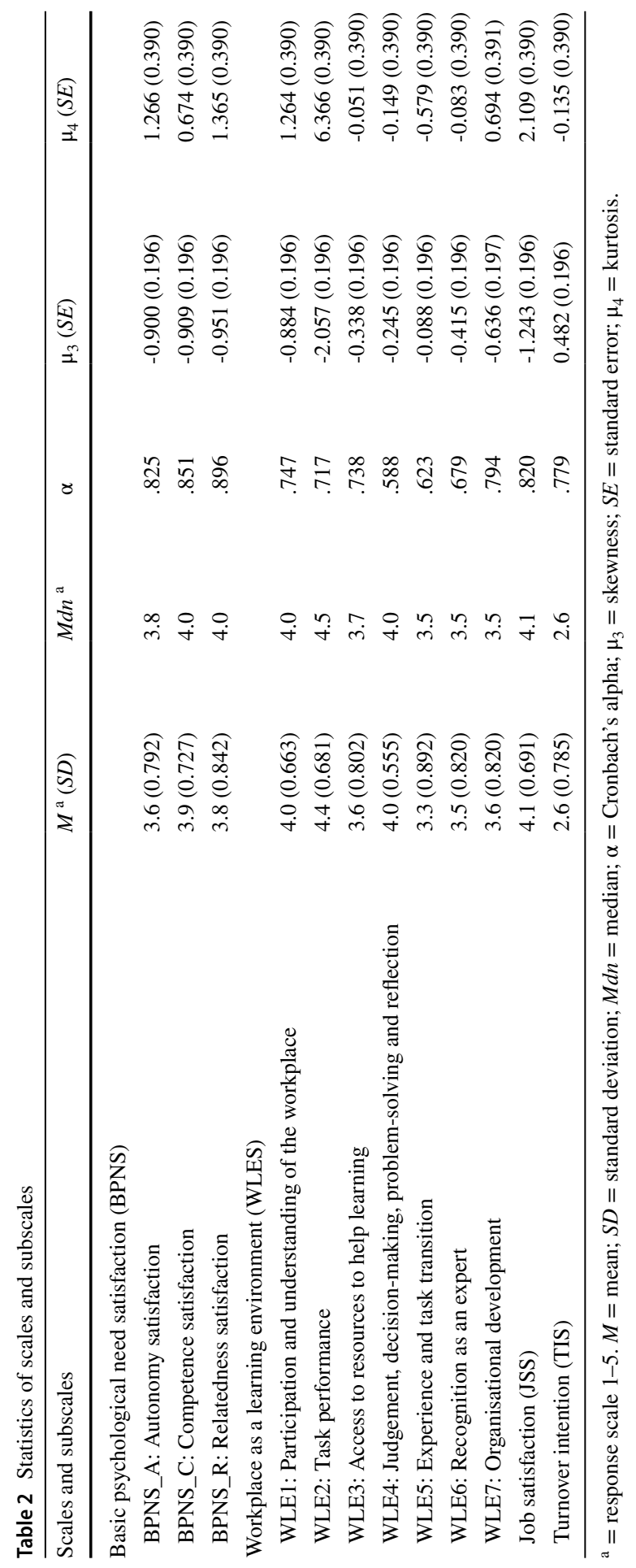


analysis model. Regarding data normality, no violations of assumptions $\left(\mu_{3}<2, \mu_{4}\right.$ $<7$; Kim, 2013) were found ( $\mu_{3}$ range from -2.057 to $0.482 ; \mu_{4}$ range from -0.149 to 6.366). Possible outliers were investigated with Mahalanobis distances. Co-occurring probability values of BPNS and WLES were greater than .001, thus winsorizing or casewise deletion was not needed (Tabachnick \& Fidell, 2013).

For the first two research questions, Pearson product-moment correlations were used to examine the associations of the BPNS and WLE dimensions within the instruments and in relation to JS and TI. Analyses related to RQ1 and RQ2 were conducted using IBM SPSS Statistics 25.0. For RQ3, Pearson product-moment correlations were first calculated to investigate the association between BPNS and WLE dimensions. Next, observed and latent variable path analysis (e.g., Bollen, 1989) were conducted to investigate the relation of BPNS and WLE on JS and TI. Observed variable path analysis (an extension of multiple regression) was applied to investigate the predictive power of BPNS and WLE in JS and TI. Following this, latent variable path analysis allowed investigation of regressions among the latent variables (structural model). Maximum likelihood estimates were calculated for the following model parameters: regression weights, variances, covariances and means of exogenous variables, and intercepts for predicting endogenous variables. In addition, squared multiple correlations, correlations among the exogenous variables, and standardized regression weights were calculated. The average values of items measuring BPNS_A, BPNS_C, and BPNS_R were the factor indicators of BPNS (see Appendix). The factor indicators of the expansiveness of WLE were the seven dimensions of WLES (see Appendix). The factor indicators of JS and TI were the average values of the three-item MOAQ-JSS and the four-item TIS (see Appendix). Results were controlled for participants' organization (dichotomous variable), gender (dichotomous variable), age (continuous variable), and total work experience (continuous variable). Analyses related to RQ3 were conducted using Mplus 8.3 software (Muthén \& Muthén, 1998-2017).

\section{Results}

\section{RQ1: Is employees' BPNS in the workplace associated with JS and TI?}

\section{Hypotheses 1 and 2}

The correlation analysis (Table 3) shows that all three BPNS dimensions are positively associated with each other, supporting H1. According to discussion related to effect sizes (Cohen, 1988, pp. 78-80), the strength of these correlations varies from small to large (small: $r=.1$, medium: $r=.3$, large: $r=.5$ ). Consistent with existing research, we found medium to large positive associations between the BPNS dimensions (Table 3). As expected, the strongest correlation was between BPNS_A and BPNS_C $(r=.57)$. We found no correlations between the three BPNS dimensions 


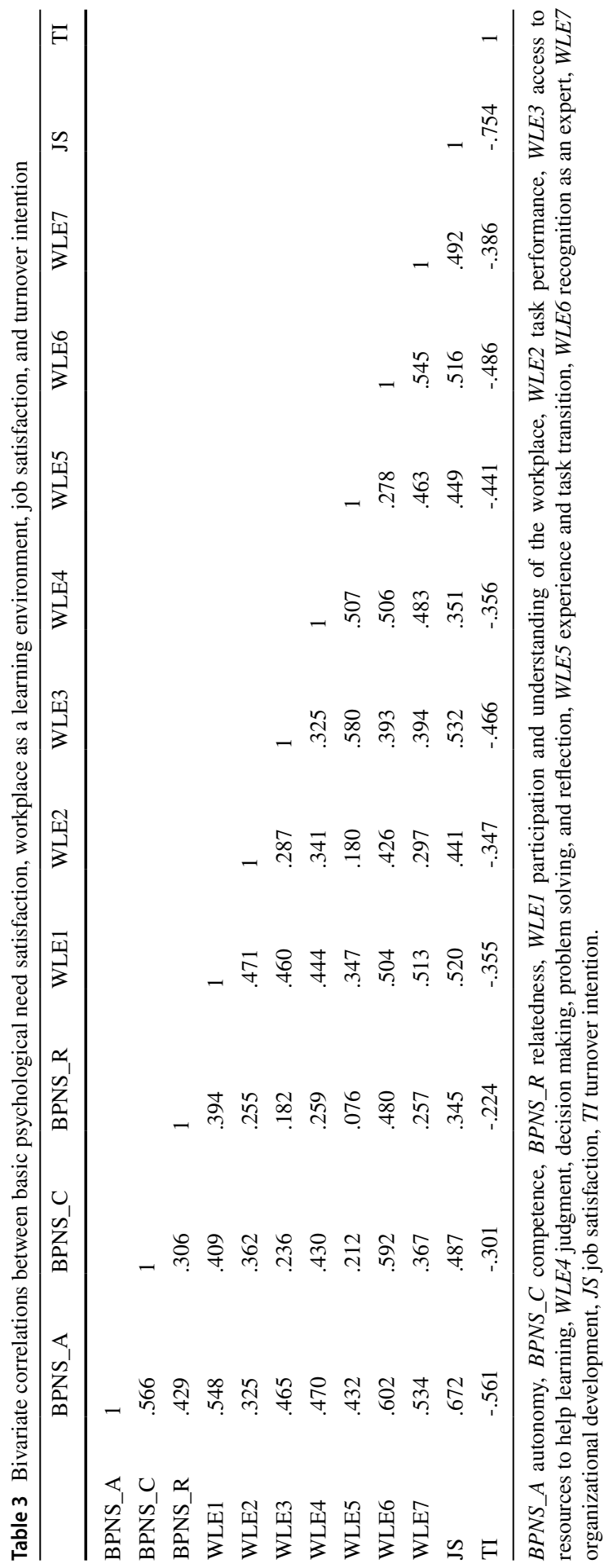


and participants' organization, gender, age, and total work experience. As shown in Table 3, all BPNS dimensions are positively correlated with JS and negatively correlated with $\mathrm{TI}$, supporting $\mathrm{H} 2$.

\section{RQ2: Is the expansiveness of employees' WLE associated with JS and TI?}

\section{Hypotheses 3 and 4}

Table 3 shows that all seven WLE dimensions are positively correlated with each other $(r=.18-.58)$, which is in line with H3. Nokelainen et al. (2018) found three strong $(r=.5$; Cohen, 1988) correlations among the WLE dimensions (WLE1-WLE2: $r=.71$, WLE2-WLE4: $r=.60$, WLE3-WLE5: $r=.60$ ). Only the last association was replicated in our study $(r=.58)$. The correlation analysis of demographic information showed that participants' total work experience was not related to the seven WLE dimensions. However, participants' organization $(r=.46)$, gender $(r=.21)$, and age $(r=-.23)$ were correlated with WLE5, and their organization $(r=.24)$ and gender $(r=.21)$ were correlated with WLE4. As shown in Table 3, all WLE dimensions had medium to large positive correlations with JS ( $r=$ $.35-.53)$ and negative correlations with TI ( $r=-.35--.49)$, supporting H4.

\section{RQ3: Are the employees' level of BPNS and the expansiveness of the WLE examined together related to JS and TI and which dimensions of BPNS and WLE have the strongest relationships with JS and TI?}

\section{Hypotheses 5 and 6}

Table 3 shows that all correlations between the dimensions of BPNS and WLE are positive $(r=.08-.60)$, supporting H5. Notably large correlations $(r>.50)$ exist between BPNC_A and WLE1 $(r=.55)$, BPNS_A and WLE6 $(r=.60)$, BPNS_A and WLE7 $(r=.53)$, and BPNS_C and WLE6 $(r=.59)$. JS had a strong negative correlation with TI $(r=-.75)$, supporting H6.

\section{Hypothesis 7}

To test H7, associations between BPNS, WLE, JS, and TI were further investigated with latent variable path analysis (e.g., Bollen, 1989). Fit indices for the models (latent regression model and two separate path analysis) are presented in table 4. Figure 2 shows the initial latent regression model that produced quite poor fit indices (Table 4: Initial model) mostly due to the relatively small sample size for a complex model (16 observed and 4 latent variables). However, the model fit indices improved considerably after allowing covariance a) between competence satisfaction (BPNS_C) and expertise recognition (WLE6), and b) among the WLE dimensions that are related to prerequisites of expertise development (between WLE3: access 
Table 4 Fit indices for the models

\begin{tabular}{llllllll}
\hline Model & $\chi^{2}(\mathrm{df})$ & $p$ & RMSEA & $90 \%$ CI RMSEA & SRMR & CFI & TLI \\
\hline $\begin{array}{l}\text { Initial model: BPNS-WLE- } \\
\text { JS-TI }\end{array}$ & $241.214(90)$ & $<.001$ & 0.108 & $0.092-0.125$ & 0.085 & 0.821 & 0.773 \\
$\begin{array}{l}\text { Modified model: BPNS- } \\
\quad \text { WLE-JS-TI }\end{array}$ & $103.891(47)$ & $<.001$ & 0.089 & $0.066-0.112$ & 0.052 & 0.934 & 0.907 \\
$\begin{array}{l}\text { BPNS-JS-TI } \\
\text { WLE-JS-TI }\end{array}$ & $21.944(16)$ & .145 & 0.051 & $0.000-0.099$ & 0.042 & 0.980 & 0.980 \\
\hline
\end{tabular}

Modified model allows covariance between BPNS_C and WLE6 dimensions, and between WLE3 and WLE5, and between WLE4 and WLE5; $\chi^{2}=$ chi-square value, $d f$ degrees of freedom, $R M S E A$ root mean square error of approximation, 90\% CI RMSEA $90 \%$ confidence interval of RMSEA, SRMR standardized root mean square residual, CFI comparative fit index, TLI Tucker Lewis index.

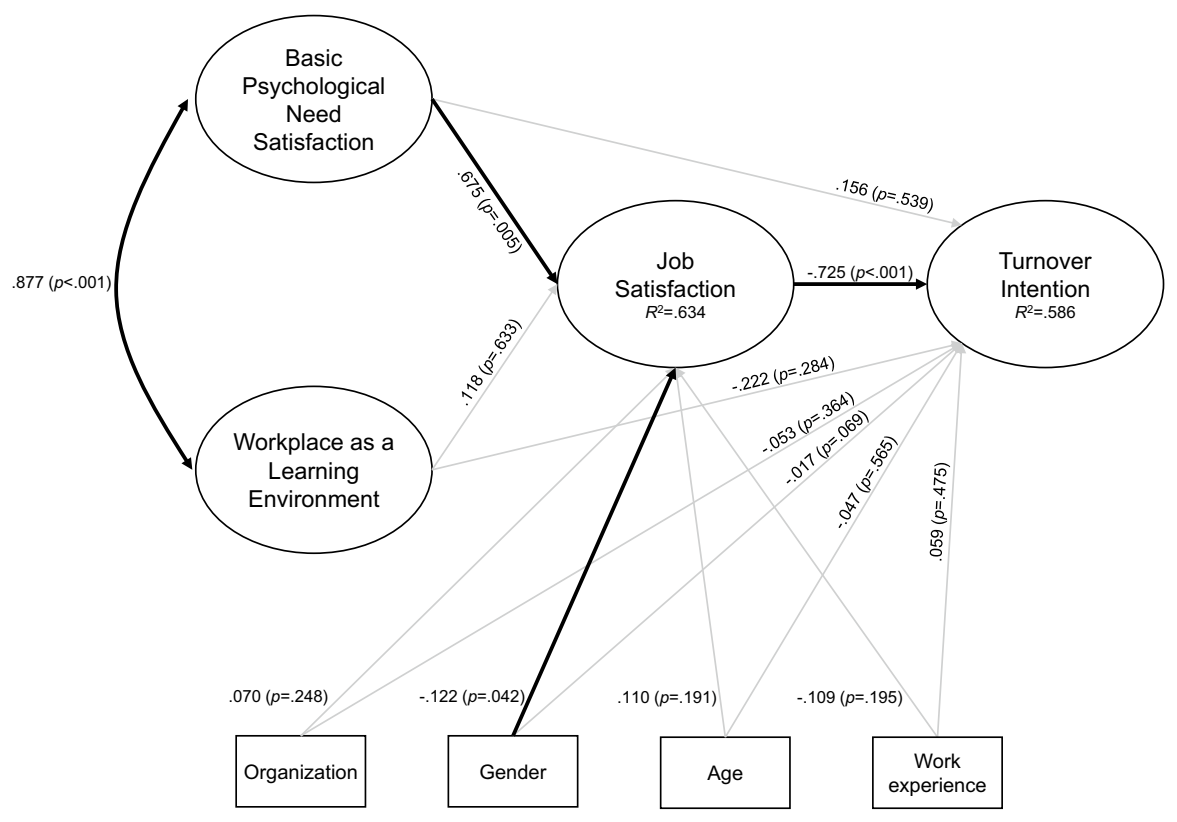

Fig. 2 Latent regression analysis of the relationships between basic psychological need satisfaction, workplace as a learning environment, job satisfaction, and turnover intention after controlling for organization, gender, age, and total work experience

to learning resources and WLE5: developing skills through task transition, and between WLE4: self-monitoring in non-routine work tasks and WLE5) (Table 4: Modified model). When the relationships of BPNS with JS and TI were investigated separately (Figure 3) both incremental (CFI >.90; TLI >.90) and absolute (RMSEA $<.05$; SRMR <.05) fit indices were good (Table 4, for details about the fit index cutoff criteria see Hu \& Bentler, 1999). However, a similar analysis with WLE as a predictor of JS and TI (Figure 4) showed less satisfactory fit values most likely due to the high number (7) of factor indicators compared to the sample size. 


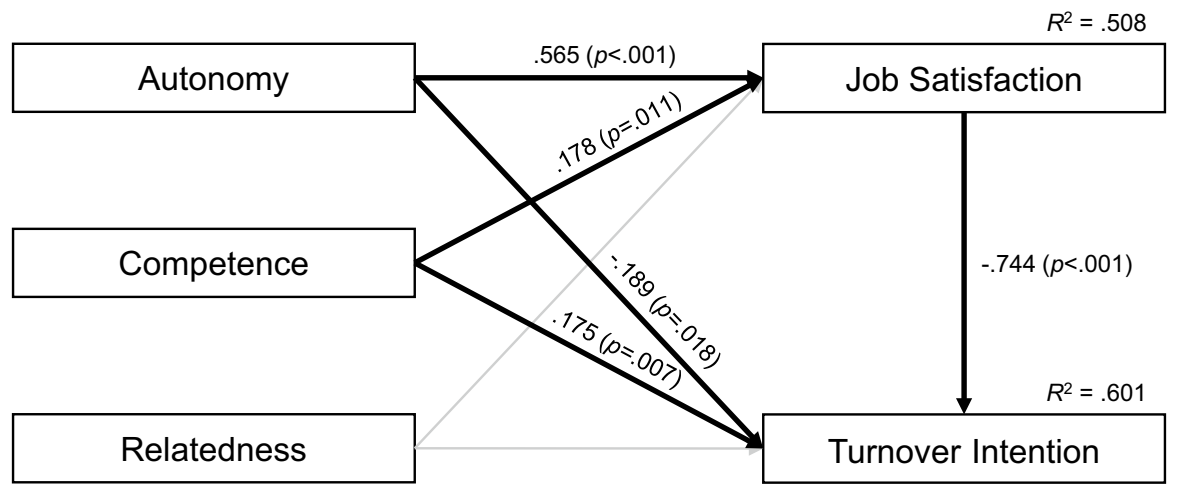

Fig. 3 Path analysis of the relationships between basic psychological need satisfaction dimensions, job satisfaction, and turnover intention after controlling for organization, gender, age, and total work experience

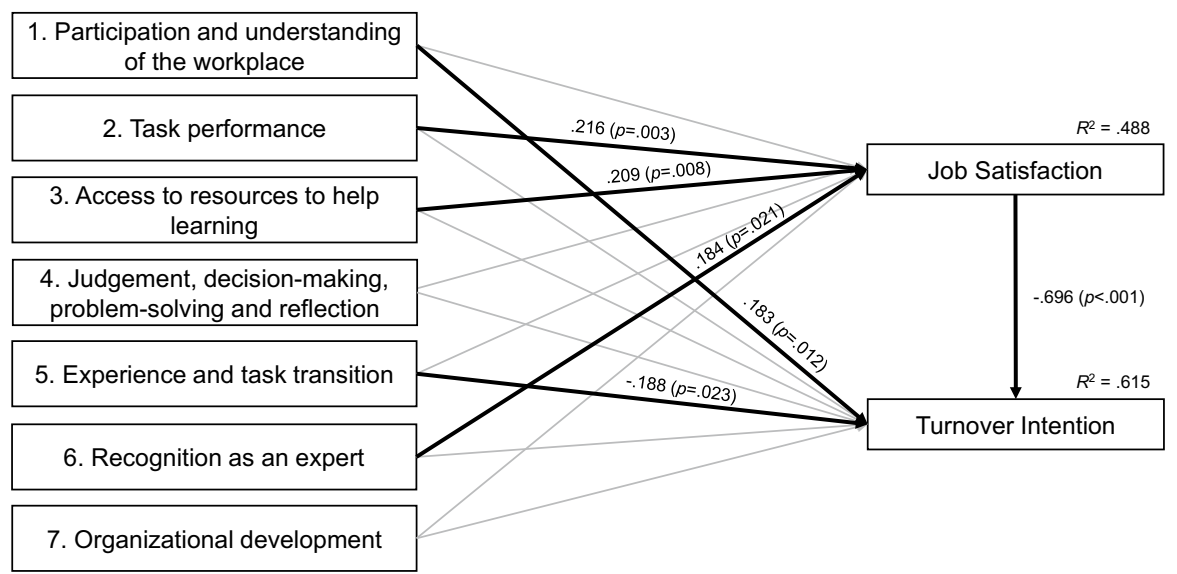

Fig. 4 Path analysis of the relationships between the dimensions of the workplace as a learning environment, job satisfaction, and turnover intention after controlling for organization, gender, age, and total work experience

The model in Figure 2 shows a strong positive association $(r=.877, p<.001)$ between BPNS and WLE, which was expected based on the correlation analysis for H5. BPNS is strongly positively related to JS $(\beta=.675, p=.005)$. Contrary to H7, BPNS has a non-significant but positive relationship with TI $(\beta=.156, p=.539)$. In line with $\mathrm{H} 7$, we found a positive (non-significant) relationship between WLE and JS $(\beta=.118, p=.633)$ and a negative (non-significant) relationship between WLE and TI $(\beta=-.222, p=.284)$. As expected, increasing JS reduces TI $(\beta=-.725$, $p<.001)$. Gender was the only control variable that had a statistically significant relationship with JS $(\beta=-.122, p=.042)$. Although the estimate is quite small, it implies that female participants reported having higher JS than males. There was no 
significant change in estimators after removing the four control variables (organization, gender, age, and total work experience). Overall, the model in Figure 2 explains quite well the variance in the two dependent variables: $63.4 \%$ of the variance in JS and $58.6 \%$ of the variance in TI.

\section{Hypothesis 8}

Path analysis with observed variables was conducted to understand further how the three BPNS factors (Figure 3) and the seven WLE factors (Figure 4) are associated with JS and TI in accordance with H8. Only statistically significant estimates are presented here. Figure 3 shows that both BPNS_A and BPNS_C are associated with JS and TI. Higher BPNS_A promotes JS $(\beta=.565, p<.001)$ and reduces the desire to change one's workplace $(\beta=-.189, p=.018)$. Higher BPNS_C has a similar positive effect on JS $(\beta=.178, p=.011)$ and on TI $(\beta=.175, p=.007)$. The model explains a considerable proportion of the variance in JS $\left(R^{2}=50.8 \%\right)$ and TI $\left(R^{2}=\right.$ $60.1 \%$ ).

Figure 4 shows that versatile work (WLE2, $\beta=.216, p=.003$ ), promotion of learning (WLE3, $\beta=.209, p=.008$ ), and acknowledgment of skills (WLE6, $\beta=$ $.184, p=.021$ ) have a positive impact on JS. Results regarding TI indicate that the more one knows about the situations and processes of the workplace (WLE1), the more likely one is to change jobs $(\beta=.183, p=.012)$. On the other hand, TI is reduced if employees have non-routine work tasks that develop their expertise $(\beta=$ $-.188, p=.023)$. The model explains a considerable proportion of the variance in JS $\left(R^{2}=48.8 \%\right)$ and TI $\left(R^{2}=61.5 \%\right)$.

\section{Discussion}

Interest in researching factors that support or hinder workplace learning and professional development has been growing in recent decades (Hager, 2011). Following this, we aimed to investigate associations between individual and environmental factors influencing workplace learning and well-being. Positioning our constructs in the 3-P model of workplace learning (Tynjälä, 2013) and the model of informal learning behaviors (Cerasoli et al., 2018), we examined the levels of BPNS and WLE expansiveness of employees of two companies representing the Finnish engineering sector, the connections between these individual factor dimensions (BPNS), environmental factor dimensions (WLE), and important job attitudes reflecting employee well-being and organizational commitment (JS and TI), and the associations of BPNS and WLE with JS and TI together after controlling for participants' organization, gender, age, and total work experience. We used central tendency and spread indicators, Pearson product-moment correlations, and structural equation modeling (observed and latent variable path analysis) for the analysis. Next, we examine in detail the results of this study reflecting our hypotheses and previous research.

The results indicate that employees' basic psychological needs were relatively well satisfied and that their workplaces as learning environments were relatively expansive. All BPNS dimensions were positively associated with each other, and 
the strength of these associations was relatively similar to those of previous studies on BPNS in the work context (Van den Broeck et al., 2016), with the exception of autonomy and competence $\left(r \_\right.$diff $\left.=+.13\right)$, which had a stronger association. As expected, positive associations between BPNS and JS and negative associations between BPNS and TI were observed. Autonomy had the strongest positive association with JS and the strongest negative association with TI. Compared with previous research (Van den Broeck et al., 2016), we observed stronger associations between BPNS_A and both JS $\left(r \_\right.$diff $\left.=+.13\right)$ and TI $\left(r \_\right.$diff $\left.=-.25\right)$ and between BPNS_C and both JS $\left(r \_\right.$diff $\left.=+.09\right)$ and TI $\left(r \_\right.$diff $\left.=-.25\right)$. We also observed weaker associations between BPNS_R and JS $\left(r \_\right.$diff $\left.=-.07\right)$ and between BPNS_R and TI ( $r \_$diff $=-.01$ ), although the differences were small. These results indicate that autonomy and competence are more impactful correlates of JS and TI compared to relatedness in this sample and possibly in this sector. These results are also congruent with notions of the importance of autonomy (e.g., Ryan \& Deci, 2000).

We found relatively high values for six of the seven WLE dimensions and moderate values for WLE5. This indicates that the structures of these workplaces might be strict and that time pressure might hinder the employees' opportunities to learn and gain knowledge, possibly due to the ubiquity of project-type work. As hypothesized, we found positive associations between all WLE dimensions but only one strong ( $r$ $=.5$; Cohen, 1988) association (WLE3 and WLE5) compared to the three strong associations found by Nokelainen et al. (2018). The small sample size could be responsible for the more moderate associations. Another possible reason is that our study sample was composed of adults, whereas the study sample of Nokelainen et al. (2018) was composed of apprentices. WLE1 had the most consistently large associations with other WLE dimensions, which suggests the relevance of participatory actions and an understanding of the workplace in determining the expansiveness of WLE. While demographic information was not correlated with BPNS, participants' organization, gender, and age were correlated with WLE5, and participants' organization and gender were correlated with WLE4. Of these demographic factors, the correlation between organization and WLE5 was the strongest. This indicates that possible differences of hierarchy in the companies could result in more moderate levels of WLE5. The results indicate that access to resources to help learning and recognition as an expert are particularly important factors of WLE with regard to JS and TI.

We found positive correlations between all BPNS and WLE dimensions. Earlier research linked BPNS_C with a concept close to WLE2 (Doornbos et al., 2008); this was the only WLE dimension that had the strongest association with BPNS_C. All the other WLE dimensions had the strongest association with BPNS_A, implying the strong impact of autonomy on WLE and the link between competence and task performance. WLE6 had high correlations with basic psychological needs indicating the importance of feedback and acknowledgement in maintaining autonomous motivation. These results emphasize the importance of autonomy and participation in the interplay between environmental and individual factors affecting workplace learning and development. As expected, JS and TI had a strong negative relationship. This 
negative association between JS and TI was slightly stronger than in previous studies ( $r \_$diff = -.06, Martin \& Roodt, 2008; $r \_$diff = -.17, Tett \& Meyer, 1993).

The observed and latent variable path analysis showed strong positive associations between the BPNS and WLE dimensions, as well as strong negative associations between JS and TI. BPNS was strongly positively related to JS and positively related to TI, although this association was non-significant. This result was unexpected and is further discussed in the next paragraph alongside the results regarding the H8. WLE was positively related to JS and negatively related to TI, but these associations were non-significant. A likely explanation for this is the high number of WLE factor indicators, which also manifested in poor fit values when WLE was used as a predictor of JS and TI. It is also possible that the WLES instrument provides more accurate results in the apprenticeship context (Nokelainen et al., 2018) than in the regular workforce context, as apprentices can have stronger and more explicit learning focus in work. Gender was the only control variable that had a statistically significant association with JS, implying that female participants reported higher JS levels than males. Although there is uncertainty regarding gender differences in JS on a large scale, research indicates that gender influences dimensions of JS (e.g., interpersonal relationships and job conditions) that have an impact on the levels of JS (García-Bernal et al., 2005). All in all, the model including BPNS and WLE seems to explain the variance in JS and TI well, as indicated by the relatively high R-squared values.

As expected, higher BPNS_A was associated with higher JS and lower TI. Higher BPNS_C was associated with higher JS and, interestingly, higher TI. This sheds light on the unexpected results for H7, where BPNS had a positive though non-significant association with TI. The positive relationship between BPNS_C and TI was also observed by Van den Broeck et al. (2016) in their meta-analysis when using relative weight analysis (i.e., when the shared variance of autonomy and relatedness is accounted for; Johnson, 2000; LeBreton \& Tonidandel, 2008) but not when using sample-weighted mean correlation. While pointing out the possibility of a suppression effect, Van den Broeck et al. (2016) speculated that employees who have a greater feeling of competence may acknowledge the potential value of their skills and knowledge to different employees, thus lowering their organizational commitment. Another possible explanation is that the higher the person's self-perceived capability, the more likely that person is to change workplaces in the near future, perhaps due to a lack of challenging work tasks or the lower possibility of promotion. Relatedness was not significantly associated with either JS or TI, contrary to $\mathrm{H} 2$. This result, however, may align with the understanding of intrinsic motivation and JS: autonomy and competence are more essential to intrinsic motivation than relatedness (Deci \& Ryan, 2000), and intrinsic motivation is associated with JS (e.g., Stringer et al., 2011). Similarly, a negative association between intrinsic motivation and TI has been observed (e.g., Dysvik \& Kuvaas, 2010). It is also possible that relatedness has less impact on employee JS and TI in this context, for example, due to the more project-oriented or independent work.

With regard to the associations between specific WLE dimensions and JS and TI, the results indicate that versatile work (the use of different skills), promotion of learning, and acknowledgment of skills and support in their development have a 
positive impact on JS. An interesting finding is that the more one knows about the situations and processes of the workplace, the more likely one is to change jobs. This result is linked to the unexpected positive association between competence and TI. It is possible that after gaining an understanding and knowledge of workplace processes, one may no longer see opportunities for promotion and may aim to seek challenges elsewhere. However, this factor can be highly organization and sector specific. Thus, when an employee learns about possibly problematic organizational processes and culture, an increase in TI is understandable. In addition, lower TI was associated with greater work task variety and time to work through tasks to develop skills. This means that a workplace environment that provides task variety but still allows adequate time to complete tasks is linked to lower TI.

The dimensions of WLE had positive associations with all BPNS dimensions, especially with BPNS_A. While this supports the reciprocal idea of expansive WLE and motivation (originating from BPNS) that is needed both in optimal performance and learning (Ryan \& Deci, 2017), there are resemblances between WLE and BPNS both in terms of theory and measurement apropos of workplace learning. These are due to workplace learning being constituted of the interplay between environmental and individual factors (e.g., Billett, 2001; Ellström, 2011). Additionally, the WLES has a closely similar item (WLE4 2. item: "I am allowed to make decisions of my own in my job.") with BPNS_A (autonomy satisfaction). Although the role of WLE4 dimension was minor in our analysis, the mapping and isolating the theoretical and measurement related dimensions between WLE and BPNS is thus important in future studies (e.g., omitting the WLES4_2 item or dimension). Notwithstanding these challenges, there are many appropriate and complementary dimensions of WLE and BPNS to use together when examining workplace learning (e.g., BPNS_C and WLE6: introspective competence and outside recognition of expertise).

Positive associations between WLE, BPNS and JS indicate a close connection between learning and well-being at work, even though the directions of these influences cannot be inferred from the results of this study. The results regarding TI, on the other hand, bring forth more ambiguous interpretations, as both BPNS_C and WLE1 had associations contrary to our hypotheses with TI. It is possible that the connection of TI to workplace learning has more individual variance, or there are stronger mediating influences (e.g., JS mediating the relationship between TI and learning culture; Egan et al., 2004). Mediation analysis with larger sample size and longitudinal measures could clarify the associations further.

\section{Limitations}

This study has several limitations that need to be taken into account when interpreting the results. The relatively small sample size affects the fit of the structural equation model, as seen in the moderate fit indices of the latent regression model and when using WLE as a predictor of JS and TI, due to the high number of factor indicators. However, applying information from the modification indexes in a theoretically justifiable manner (Saris et al., 2009) resulted in improved latent path model fit. Furthermore, the multidimensionality of the WLE4 dimension, which 
manifests in low alpha value, indicates that the structure of the WLES might need further development.

The study participants were from two relatively heterogeneous companies in terms of size and structure, operating in the male- dominated engineering sector. These demographic factors limit the generalizability of the results. Our results are based on cross-sectional self-reported data. Even though self-reports are appropriate for collecting data on self-perceptual concepts (Chan, 2009), the cross-sectional nature of the data prevents causal and predictive interpretations of the results. While our questionnaire for JS (MOAQ-JSS; see Bowling \& Hammond, 2008) included the affective component, which many commonly used instruments lack (e.g., Minnesota Satisfaction Questionnaire; Weiss et al., 1967), it is a shortened version of an instrument that is over 40 years old (Cammann et al., 1979). We also did not include the frustration component in our measures of BPNS to keep the questionnaire length reasonable.

\section{Conclusions and Implications}

The results of this study support the idea that BPNS and WLE are associated with employee JS and TI. Simple associations between individual factors were congruent with the findings of previous research and supported our hypotheses that 1) BPNS is associated with higher JS and lower TI, 2) WLE is associated with higher JS and lower TI, and 3) BPNS, WLE, JS, and TI all have high intercorrelations. The results from observed and latent variable path analysis revealed that high BPNS_A and BPNS_C, versatile work, promotion of learning, and acknowledgment of skills and support in their development were positively related to JS. The results also showed that high BPNS_A and non-routine work tasks that develop expertise were negatively related to TI. Contrary to expectations, BPNS_C was positively associated with TI. An unexpected association was also found between WLE1 (participation and understanding of the workplace) and TI, indicating that the more one knows about the situations and processes of the workplace, the more likely one is to change jobs.

The study results support and raise notions to both theory and practice. In a theoretical sense, the results support the importance of autonomy satisfaction in work context and strengthen the connection between learning and well-being at work by connecting characteristics of an expansive WLE to JS and BPNS. Results also highlight the ambiguous nature of TI and suggest that TI is not necessarily associated with only negative conditions or perceptions. Strong associations between BPNS and perceptions of acknowledgement and recognition from others at work indicate the importance of feedback and acknowledgement of work in maintaining employee motivation. In practical terms, the results from the model encourage employers of STEM fields to provide employees versatile, autonomous work to improve wellbeing, but also to acknowledge the importance of clear communication and dialogue between employer and employee in order to improve the retention of and developing competent workforce. 


\section{Recommendations for Future Research}

Holding on to competent employees is of utmost importance in business today; thus, future studies should aim to further examine the association between BPNS_C and TI, as well as identify possible actions to influence this association. While data collected via questionnaires capture the nature of the factors in this study relatively well, it would be interesting to include objective measures connected to learning and wellbeing. The transient and longitudinal associations and causal links of these studied constructs can be examined with longitudinal studies and bigger samples or by adding interventions. Many factors examined in this study are included in or strongly related to happiness-related constructs in the workplace (Fisher, 2010). While there is initial evidence for formal learning interventions in the workplace having positive effects on well-being (see Watson et al., 2018), connections between happiness or well-being and informal learning in the workplace have been less researched. This gap could be investigated by measuring well-being (e.g., stress) during authentic learning situations in the workplace in addition to self-reported data.

\section{Appendix}

\begin{tabular}{|c|c|c|c|}
\hline Scales, subscales, and items & $M(S D)$ & Skewness $(S E)$ & Kurtosis $(S E)$ \\
\hline \multicolumn{4}{|l|}{ Basic psychological need satisfaction } \\
\hline 1. Autonomy satisfaction $(\alpha=.825)$ & {$[3.6(0.792)]$} & {$[-0.900(0.196)]$} & {$[1.266(0.390)]$} \\
\hline $\begin{array}{l}\text { At work, I feel a sense of choice and freedom in the } \\
\text { things I undertake. }\end{array}$ & $3.6(1.054)$ & $-0.561(0.196)$ & $-0.223(0.390)$ \\
\hline $\begin{array}{l}\text { I feel that my decisions on my job reflect what I } \\
\text { really want. }\end{array}$ & $3.6(0.952)$ & $-0.784(0.196)$ & $1.091(0.390)$ \\
\hline I feel my choices on my job express who I really am. & $3.7(0.963)$ & $-0.762(0.196)$ & $0.221(0.390)$ \\
\hline $\begin{array}{l}\text { I feel I have been doing what really interests me in } \\
\text { my job. }\end{array}$ & $3.7(0.942)$ & $-0.767(0.196)$ & $0.657(0.390)$ \\
\hline 2. Competence satisfaction $(\alpha=.851)$ & {$[3.9(0.727)]$} & {$[-0.909(0.196)]$} & {$[0.674(0.390)]$} \\
\hline I feel confident that I can do things well on my job. & $3.8(0.998)$ & $-0.817(0.196)$ & $0.450(0.390)$ \\
\hline At work, I feel capable at what I do. & $3.8(0.904)$ & $-0.848(0.196)$ & $0.794(0.390)$ \\
\hline $\begin{array}{l}\text { When I am at work, I feel competent to achieve my } \\
\text { goals. }\end{array}$ & $4.0(0.752)$ & $-0.616(0.196)$ & $0.488(0.390)$ \\
\hline $\begin{array}{l}\text { In my job, I feel I can successfully complete difficult } \\
\text { tasks. }\end{array}$ & $4.0(0.826)$ & $-1.324(0.196)$ & $3.762(0.390)$ \\
\hline 3. Relatedness satisfaction $(\alpha=.896)$ & {$[3.8(0.842)]$} & {$[-0.951(0.196)]$} & {$[1.365(0.390)]$} \\
\hline $\begin{array}{l}\text { I feel that the people I care at work about also care } \\
\text { about me. }\end{array}$ & $4.0(0.910)$ & $-0.822(0.196)$ & $0.537(0.390)$ \\
\hline $\begin{array}{l}\text { I feel connected with people who care for me at } \\
\text { work, and for whom I care at work. }\end{array}$ & $3.9(1.002)$ & $-0.781(0.196)$ & $0.104(0.390)$ \\
\hline $\begin{array}{l}\text { At work, I feel close and connected with other people } \\
\text { who are important to me. }\end{array}$ & $3.6(0.991)$ & $-0.664(0.196)$ & $0.315(0.390)$ \\
\hline $\begin{array}{l}\text { I experience a warm feeling with the people I spend } \\
\text { time with at work. }\end{array}$ & $3.8(0.957)$ & $-0.662(0.196)$ & $0.168(0.390)$ \\
\hline
\end{tabular}


Workplace as a learning environment

1. Participation and understanding of the workplace $(\alpha=.747)$

I participate in and understand a variety of situations and processes in my workplace.

I know at the general level what work my colleagues in this workplace do.

I understand the goals and aims of my workplace.

2. Task performance $(\alpha=.717)$

I tackle complex problems in my work.

My work is not one-sided, I am expected to use a versatile set of skills in my work.

3. Access to resources to help learning ( $\alpha=$.738)

I receive feedback/mentoring/coaching at work (for example from other workers).

I have access to necessary resources to help me learn (for example other workers, materials, customers, competitors, suppliers and professional networks).

I am encouraged to gain qualification(s).

[4.0(0.663)] [-0.884(0.196)] [1.264(0.390)]

$3.8(0.877) \quad-0.642(0.196) \quad 0.168(0.390)$

$4.2(0.741) \quad-0.641(0.196) \quad 0.274(0.390)$

$4.1(0.815) \quad-1.326(0.196) \quad 2.701(0.390)$

[4.4(0.681)] [-2.057(0.196)] [6.366(0.390)]

$4.4(0.748) \quad-1.700(0.196) \quad 4.631(0.390)$

$4.5(0.794) \quad-2.192(0.196) \quad 7.687(0.390)$

[3.6 (0.802)] [-0.338(0.196)] [-0.051(0.390)]

$3.4(1.018) \quad-0.287(0.196) \quad-0.592(0.390)$

$3.9(0.836) \quad-0.754(0.196) \quad 0.987(0.390)$

$3.6(1.100) \quad-0.278(0.196) \quad-0.928(0.390)$

4. Judgement, decision-making, problem-solving and reflection $(\alpha=.588)$

I assess my own performance at work.

I am allowed to make decisions of my own in my job.

Solving problems related to my area of expertise is an essential part of my work.

I have time to reflect on my work performance.

5. Experience and task transition $(\alpha=.623)$

I gain experience across various work tasks in the workplace.

I am given time to work through tasks to develop my skills and knowledge.

6. Recognition as an expert $(\alpha=.679)$

I receive acknowledgement in my job from colleagues or superior(s) (for example in the development of my expertise and my achievements).

My colleagues or superior(s) recognize me as an expert of my field.

7. Organisational development $(\alpha=.794)$

My own vision of how the field I am working on (e.g., "bridge construction", "software development") should develop in the future is in line with the vision of this workplace.

The business-related goals of the workplace (for

$-0.693(0.196) \quad 0.221(0.390)$

$4.3(0.912)$

$-1.966(0.196)$

$5.659(0.390)$

$3.4(0.902) \quad-0.102(0.196) \quad-0.627(0.390)$

[3.3(0.892)] [-0.088(0.196)] [-0.579(0.390)]

$3.4(1.044) \quad-0.412(0.196) \quad-0.443(0.390)$

$3.1(1.050) \quad 0.147(0.196) \quad-0.732(0.390)$

[3.5 (0.820)] [-0.415(0.196)] [-0.083(0.390)]

$3.4(0.963) \quad-0.313(0.196) \quad-0.453(0.390)$

$3.6(0.922) \quad-0.294(0.196) \quad-0.479(0.390)$

[3.6(0.820)] [-0.636(0.197)] [0.694(0.391)]

$3.7(0.925) \quad-0.878(0.196) \quad 1.592(0.390)$ example what kind of projects to take part in) are in line with my own goals to develop my professional skills.

Job satisfaction $(\alpha=.820)$

[4.1(0.691)] [-1.243(0.196)] [2.109(0.390)]

All in all, I am satisfied with my job.

$3.9(0.812) \quad-1.073(0.196) \quad 1.830(0.390)$




\begin{tabular}{|c|c|c|c|}
\hline Scales, subscales, and items & $M(S D)$ & Skewness $(S E)$ & Kurtosis $(S E)$ \\
\hline In general, I don't like my job. (reverse coded) & $1.7(0.856)$ & $1.436(0.196)$ & $2.017(0.390)$ \\
\hline In general, I like working here. & $4.2(0.744)$ & $-0.686(0.196)$ & $0.306(0.390)$ \\
\hline Turnover intention $(\alpha=.779)$ & {$[2.6(0.785)]$} & {$[0.482(0.196)]$} & {$[-0.135(0.390)]$} \\
\hline $\begin{array}{l}\text { How often are you frustrated when not given the } \\
\text { opportunity at work to achieve your personal work- } \\
\text { related goals? }\end{array}$ & $2.5(0.939)$ & $0.424(0.196)$ & $-0.396(0.390)$ \\
\hline $\begin{array}{l}\text { How often are your personal values at work compro- } \\
\text { mised? }\end{array}$ & $2.3(0.993)$ & $0.622(0.196)$ & $-0.126(0.390)$ \\
\hline $\begin{array}{l}\text { How often do you dream about getting another job } \\
\text { that will better suit your personal needs? }\end{array}$ & $2.7(1.154)$ & $0.097(0.196)$ & $-1.020(0.390)$ \\
\hline $\begin{array}{l}\text { How often do you look forward to another day at } \\
\text { work? (reverse coded) }\end{array}$ & $3.2(0.949)$ & $-0.375(0.196)$ & $-0.178(0.390)$ \\
\hline
\end{tabular}

Values in square brackets represent subscale average values (factor indicators).

Acknowledgments The authors wish to thank Eija Lehtonen, Heta Rintala, Sonja Niiranen, Jenni Piirto, and Tiia Lehtinen for their help in the data collection phase of this study.

Funding This research was funded by the Finnish Work Environment Fund (project 118083).

Data Availability Not applicable.

Code Availability Not applicable.

\section{Declarations}

Ethics Approval Not applicable.

Consent to Participate Not applicable.

Consent for Publication Not applicable.

Conflicts of Interest The authors declare that they have no conflict of interest.

Open Access This article is licensed under a Creative Commons Attribution 4.0 International License, which permits use, sharing, adaptation, distribution and reproduction in any medium or format, as long as you give appropriate credit to the original author(s) and the source, provide a link to the Creative Commons licence, and indicate if changes were made. The images or other third party material in this article are included in the article's Creative Commons licence, unless indicated otherwise in a credit line to the material. If material is not included in the article's Creative Commons licence and your intended use is not permitted by statutory regulation or exceeds the permitted use, you will need to obtain permission directly from the copyright holder. To view a copy of this licence, visit http://creativecommons.org/licen ses/by/4.0/.

\section{References}

Bakker, A. B., \& Demerouti, E. (2007). The job demands-resources model: State of the art. Journal of Managerial Psychology, 22(3), 309-328. https://doi.org/10.1108/02683940710733115. 
Berg, S. A., \& Chyung, S. Y. (2008). Factors that influence informal learning in the workplace. Journal of Workplace Learning, 20(4), 229-244. https://doi.org/10.1108/13665620810871097.

Biggs, J. (1993). What do inventories of students' learning processes really measure? A theoretical review and clarification. British Journal of Educational Psychology, 63(1), 3-19. https://doi.org/10.1111/j. 2044-8279.1993.tb01038.x.

Billett, S. (2001). Learning through work: Workplace affordances and individual engagement. Journal of Workplace Learning, 13(5), 209-214. https://doi.org/10.1108/EUM0000000005548.

Billett, S., \& Henderson, A. (2011). Developing learning professionals. Springer. https://doi.org/10.1007/ 978-90-481-3937-8.

Billett, S., Harteis, C., \& Eteläpelto, A. (2008). Emerging perspectives of workplace learning. Sense. https://doi.org/10.1163/9789087906450.

Bollen, K. (1989). Structural equations with latent variables. John Wiley \& Sons. https://doi.org/10. 1002/9781118619179.

Bothma, C. F. C., \& Roodt, G. (2013). The validation of the turnover intention scale. Journal of Human Resource Management, 11, 1-11. https://doi.org/10.4102/sajhrm.v11i1.507.

Bowling, N. A., \& Hammond, G. D. (2008). A meta-analytic examination of the construct validity of the Michigan Organizational Assessment Questionnaire Job Satisfaction Subscale. Journal of Vocational Behavior, 73, 63-77. https://doi.org/10.1016/j.jvb.2008.01.004.

Bowling, N. A., Eschleman, K. J., \& Wang, Q. (2010). A meta-analytic examination of the relationship between job satisfaction and subjective well-being. Journal of Occupational and Organizational Psychology, 83(4), 915-934. https://doi.org/10.1348/096317909X478557.

Brief, A. P. (1998). Attitudes in and around organizations. Sage.

Cammann, C., Fichman, M., Jenkins, D., \& Klesh, J. (1979). The Michigan Organizational Assessment Questionnaire. University of Michigan.

Cerasoli, C. P., Alliger, G. M., Donsbach, J. S., Mathieu, J. E., Tannenbaum, S. I., \& Orvis, K. A. (2018). Antecedents and outcomes of informal learning behaviors: A meta-analysis. Journal of Business and Psychology, 33(2), 203-230. https://doi.org/10.1007/s10869-017-9492-y.

Chan, D. (2009). So why ask me? Are self-report data really that bad? In C. E. Lance \& R. J. Vandenberg (Eds.), Statistical and methodological myths and urban legends: Received doctrine, verity, and fable in the organizational and social sciences (pp. 311-338). Routledge.

Chen, B., Vansteenkiste, M., Beyers, W., Boone, L., Deci, E. L., Van der Kaap-Deeder, J., et al. (2015). Basic psychological need satisfaction, need frustration, and need strength across four cultures. Motivation and Emotion, 39(2), 216-236. https://doi.org/10.1007/s11031-014-9450-1.

Chiva, R., \& Alegre, J. (2008). Emotional intelligence and job satisfaction: The role of organizational learning capability. Personnel Review, 37(6), 680-701. https://doi.org/10.1108/004834808109069 00 .

Clarke, N. (2005). Workplace learning environment and its relationship with learning outcomes in healthcare organizations. Human Resource Development International, 8(2), 185-205. https://doi.org/10. 1080/13678860500100228.

Coetzer, A., Kock, H., \& Wallo, A. (2017). Distinctive characteristics of small businesses as sites for informal learning. Human Resource Development Review, 16(2), 111-134. https://doi.org/10.1177/ 1534484317704291.

Cohen, J. (1988). Statistical power analysis for the behavioral sciences. Erlbaum. https://doi.org/10.4324/ 9780203771587.

Cronbach, L. J. (1951). Coefficient alpha and the internal structure of tests. Psychometrika, 16, 297-334. https://doi.org/10.1007/BF02310555.

Deci, E. L., \& Ryan, R. M. (1985). The general causality orientations scale: Self-determination in personality. Journal of Research in Personality, 19(2), 109-134. https://doi.org/10.1016/0092-6566(85) 90023-6.

Deci, E. L., \& Ryan, R. M. (2000). The "what" and "why" of goal pursuits: Human needs and the selfdetermination of behavior. Psychological Inquiry, 11(4), 227-268. https://doi.org/10.1207/S1532 7965PLI1104_01.

Doornbos, A. J., Simons, R. J., \& Denessen, E. (2008). Relations between characteristics of workplace practices and types of informal work-related learning: A survey study among Dutch police. Human Resource Development Quarterly, 19(2), 129-151. https://doi.org/10.1002/hrdq.1231.

Dunkin, M. J., \& Biddle, B. J. (1974). The study of teaching. Holt, Rinehart \& Winston. 
Dysvik, A., \& Kuvaas, B. (2010). Exploring the relative and combined influence of mastery-approach goals and work intrinsic motivation on employee turnover intention. Personnel Review, 39(5), 622638. https://doi.org/10.1108/00483481011064172.

Egan, T. M., Yang, B., \& Bartlett, K. R. (2004). The effects of organizational learning culture and job satisfaction on motivation to transfer learning and turnover intention. Human Resource Development Quarterly, 15(3), 279-301. https://doi.org/10.1002/hrdq.1104.

Ellström, P. -E. (2001). Integrating learning and work: Problems and prospects. Human Resource Development Quarterly, 12(4), 421-435. https://doi.org/10.1002/hrdq.1006.

Ellström, P. -E. (2011). Informal learning at work: Conditions, processes and logics. In M. Malloch, L. Cairns, K. Evans, \& B. O'Connor (Eds.), The SAGE handbook of workplace learning (pp. 105119). Sage.

Engeström, Y. (2001). Expansive learning at work: Toward an activity theoretical reconceptualization. Journal of Education and Work, 14, 133-156. https://doi.org/10.1080/13639080020028747.

Eraut, M. (2004). Informal learning in the workplace. Studies in Continuing Education, 26(2), 247-273. https://doi.org/10.1080/158037042000225245.

Felstead, A., Gallie, D., Green, F., \& Inanc, H. (2015). Fits, misfits and interactions: Learning at work, job satisfaction and job-related well-being. Human Resource Management Journal, 25(3), 294-310. https://doi.org/10.1111/1748-8583.12071.

Fisher, C. D. (2010). Happiness at work. International Journal of Management Reviews, 12(4), 384-412. https://doi.org/10.1111/j.1468-2370.2009.00270.x.

Fuller, A., \& Unwin, L. (2003). Learning as apprentices in the contemporary UK workplace. Journal of Education and Work, 16(4), 407-426. https://doi.org/10.1080/1363908032000093012.

Fuller, A., \& Unwin, L. (2004). Expansive learning environments: Integrating organizational and personal development. In H. Rainbird, A. Fuller, \& A. Munro (Eds.), Workplace learning in context (pp. 126-144). Routledge.

Fuller, A., \& Unwin, L. (2010). 'Knowledge workers' as the new apprentices: The influence of organisational autonomy, goals and values on the nurturing of expertise. Vocations and Learning, 3(3), 203-222. https://doi.org/10.1007/s12186-010-9043-4.

García-Bernal, J., Gargallo-Castel, A., Marzo-Navarro, M., \& Rivera-Torres, P. (2005). Job satisfaction: Empirical evidence of gender differences. Women in Management Review, 20(4), 279-288. https:// doi.org/10.1108/09649420510599098.

Govaerts, N., Kyndt, E., Dochy, F., \& Baert, H. (2011). Influence of learning and working climate on the retention of talented employees. Journal of Workplace Learning, 23, 35-55. https://doi.org/10.1108/ 13665621111097245.

Hager, P. (2011). Theories of workplace learning. In M. Malloch, L. Cairns, K. Evans, \& B. N. O’Connor (Eds.), The SAGE handbook of workplace learning (pp. 17-31). Sage. https://doi.org/10.4135/97814 46200940.n2.

Harteis, C., \& Billett, S. (2008). The workplace as learning environment: Introduction. International Journal of Educational Research, 4(47), 209-212. https://doi.org/10.1016/j.ijer.2008.07.002.

Hom, P. W., Lee, T. W., Shaw, J. D., \& Hausknecht, J. P. (2017). One hundred years of employee turnover theory and research. Journal of Applied Psychology, 102(3), 530-545. https://doi.org/10.1037/ap100 00103.

Hu, L., \& Bentler, P. M. (1999). Cutoff criteria for fit indexes in covariance structure analysis: Conventional criteria versus new alternatives. Structural Equation Modeling, 6(1), 1-55. https://doi.org/10. 1080/10705519909540118.

Iammartino, R., Bischoff, J., Willy, C., \& Shapiro, P. (2016). Emergence in the US Science, Technology, Engineering, and Mathematics (STEM) workforce: An agent-based model of worker attrition and group size in high-density STEM organizations. Complex \& Intelligent Systems, 2, 23-34. https:// doi.org/10.1007/s40747-016-0015-7.

Islam, T., Ahmed, I., \& Ahmad, U. N. B. U. (2015). The influence of organizational learning culture and perceived organizational support on employees' affective commitment and turnover intention. Nankai Business Review International, 6(4), 417-431. https://doi.org/10.1108/NBRI-01-2015-0002.

James, S., \& Holmes, C. (2012). Developing vocational excellence: Learning environments within work environments (SKOPE Research Paper 112). University of Oxford.

Johnson, J. W. (2000). A heuristic method for estimating the relative weight of predictor variables in multiple regression. Multivariate Behavioral Research, 35, 1-19. https://doi.org/10.1207/S15327906M BR3501_1. 
Judge, T. A., \& Kammeyer-Mueller, J. D. (2012). Job attitudes. Annual Review of Psychology, 63, 341367. https://doi.org/10.1146/annurev-psych-120710-100511.

Judge, T. A., Thoresen, C. J., Bono, J. E., \& Patton, G. K. (2001). The job satisfaction-job performance relationship: A qualitative and quantitative review. Psychological Bulletin, 127(3), 376-407. https:// doi.org/10.1037/0033-2909.127.3.376.

Judge, T. A., Weiss, H. M., Kammeyer-Mueller, J. D., \& Hulin, C. L. (2017). Job attitudes, job satisfaction, and job affect: A century of continuity and of change. Journal of Applied Psychology, 102(3), 356-374. https://doi.org/10.1037/apl0000181.

Kim, H. Y. (2013). Statistical notes for clinical researchers: Assessing normal distribution (2) using skewness and kurtosis. Restorative Dentistry \& Endodontics, 38(1), 52-54. https://doi.org/10.5395/rde. 2013.38.1.52.

Lance, C. E., Butts, M. M., \& Michels, L. C. (2006). The sources of four commonly reported cutoff criteria: What did they really say? Organizational Research Methods, 9(2), 202-220. https://doi.org/10. $1177 / 1094428105284919$.

Lave, J., \& Wenger, E. (1991). Situated learning: Legitimate peripheral participation. Cambridge University Press. https://doi.org/10.1017/CBO9780511815355.

LeBreton, J. M., \& Tonidandel, S. (2008). Multivariate relative importance: Extending relative weight analysis to multivariate criterion spaces. Journal of Applied Psychology, 93(2), 329-345. https://doi. org/10.1037/0021-9010.93.2.329.

Locke, E. A. (1976). The nature and causes of job satisfaction. In M. D. Dunnette (Ed.), Handbook of industrial and organizational psychology (pp. 1297-1347). Rand McNally.

Marsick, V. J., \& Watkins, K. E. (2003). Demonstrating the value of an organization's learning culture: The dimensions of the learning organization questionnaire. Advances in Developing Human Resources, 5(2), 132-151. https://doi.org/10.1177/1523422303005002002.

Martela, F., Ryan, R. M., \& Steger, M. F. (2018). Meaningfulness as satisfaction of autonomy, competence, relatedness, and beneficence: Comparing the four satisfactions and positive affect as predictors of meaning in life. Journal of Happiness Studies, 19(5), 1261-1282. https://doi.org/10.1007/ s10902-017-9869-7.

Martin, A., \& Roodt, G. (2008). Perceptions of organisational commitment, job satisfaction and turnover intentions in a post-merger South African tertiary institution. SA Journal of Industrial Psychology, 34(1), 23-31. https://doi.org/10.4102/sajip.v34i1.415.

Mitzel, H. E. (1960). Teacher effectiveness. In C. W. Harris (Ed.), Encyclopedia of educational research (3rd ed., pp. 1481-1486). Macmillan.

Muthén, L. K., \& Muthén, B. O. (1998-2017). Mplus User's Guide (8th). Muthén \& Muthén.

Nokelainen, P., Rintala, H., \& Pylväs, L. (2018). Apprentices' adaption and innovation styles in relation to dimensions of workplaces as learning environments. In L. Moreno Herrera, M. Teräs, \& P. Gougoulakis (Eds.), Emerging issues in vocational education \& training: Voices from cross-national research (pp. 370-388). Stockholm University Press.

Pekrun, R., \& Perry, R. P. (2014). Control-value theory of achievement emotions. In R. Pekrun \& L. Linnenbrink-Garcia (Eds.), International handbook of emotions in education (pp. 120-141). Routledge.

Rausch, A. (2013). Task characteristics and learning potentials-empirical results of three diary studies on workplace learning. Vocations and Learning, 6, 55-79. https://doi.org/10.1007/ s12186-012-9086-9.

Roca, J. C., \& Gagné, M. (2008). Understanding e-learning continuance intention in the workplace: A self-determination theory perspective. Computers in Human Behavior, 24(4), 1585-1604. https:// doi.org/10.1016/j.chb.2007.06.001.

Rowden, R. W., \& Conine, C. T. (2005). The impact of workplace learning on job satisfaction in small US commercial banks. Journal of Workplace Learning, 17(4), 215-230. https://doi.org/10.1108/ 13665620510597176.

Rubenstein, A. L., Eberly, M. B., Lee, T. W., \& Mitchell, T. R. (2018). Surveying the forest: A metaanalysis, moderator investigation, and future-oriented discussion of the antecedents of voluntary employee turnover. Personnel Psychology, 71, 23-65. https://doi.org/10.1111/peps.12226.

Ryan, R. M., \& Deci, E. L. (2000). Self-determination theory and the facilitation of intrinsic motivation, social development, and well-being. American Psychologist, 55(1), 68-78. https://doi.org/10.1037/ 0003-066X.55.1.68.

Ryan, R. M., \& Deci, E. L. (2017). Self-determination theory: Basic psychological needs in motivation, development, and wellness. Guilford. https://doi.org/10.1521/978.14625/28806 
Ryu, G., \& Moon, S. G. (2019). The effect of actual workplace learning on job satisfaction and organizational commitment. Journal of Workplace Learning, 31(8), 481-497. https://doi.org/10.1108/ JWL-05-2019-0061.

Saari, L. M., \& Judge, T. A. (2004). Employee attitudes and job satisfaction. Human Resource Management, 43(4), 395-407. https://doi.org/10.1002/hrm.20032.

Saris, W. E., Satorra, A., \& van der Veld, W. M. (2009). Testing structural equation models or detection of misspecifications? Structural Equation Modeling, 16(4), 561-582. https://doi.org/10.1080/10705 510903203433.

Schaufeli, W. B., Bakker, A. B., \& Van Rhenen, W. (2009). How changes in job demands and resources predict burnout, work engagement, and sickness absenteeism. Journal of Organizational Behavior, 30(7), 893-917. https://doi.org/10.1002/job.595.

Schultz, P. P., Ryan, R. M., Niemiec, C. P., Legate, N., \& Williams, G. C. (2015). Mindfulness, work climate, and psychological need satisfaction in employee well-being. Mindfulness, 6(5), 971-985. https://doi.org/10.1007/s12671-014-0338-7.

Sessa, V. I., \& Bowling, N. A. (2020). Essentials of job attitudes and other workplace psychological constructs. Routledge. https://doi.org/10.4324/9780429325755.

Spector, P. E. (1997). Job satisfaction: Application, assessment, causes, and consequences. Sage. https:// doi.org/10.4135/9781452231549.

Stringer, C., Didham, J., \& Theivananthampillai, P. (2011). Motivation, pay satisfaction, and job satisfaction of front-line employees. Qualitative Research in Accounting \& Management, 8(2), 161-179. https://doi.org/10.1108/11766091111137564.

Tabachnick, B. G., \& Fidell, L. S. (2013). Using multivariate statistics (6th ed.). Pearson.

Tannenbaum, S. I. (1997). Enhancing continuous learning: Diagnostic findings from multiple companies. Human Resource Management, 36(4), 437-452. https://doi.org/10.1002/(SICI)1099-050X(199724) 36:4<437::AID-HRM7>3.0.CO;2-W.

Tett, R. P., \& Meyer, J. P. (1993). Job satisfaction, organizational commitment, turnover intention, and turnover: Path analyses based on meta-analytic findings. Personnel Psychology, 46(2), 259-293. https://doi.org/10.1111/j.1744-6570.1993.tb00874.x.

Tynjälä, P. (2008). Perspectives into learning at the workplace. Educational Research Review, 3(2), 130154. https://doi.org/10.1016/j.edurev.2007.12.001.

Tynjälä, P. (2013). Toward a 3-P model of workplace learning: A literature review. Vocations and Learning, 6, 11-36. https://doi.org/10.1007/s12186-012-9091-z.

Van den Broeck, A., Vansteenkiste, M., De Witte, H., \& Lens, W. (2008). Explaining the relationships between job characteristics, burnout, and engagement: The role of basic psychological need satisfaction. Work \& Stress, 22(3), 277-294. https://doi.org/10.1080/02678370802393672.

Van den Broeck, A., Ferris, D. L., Chang, C. H., \& Rosen, C. C. (2016). A review of self-determination theory's basic psychological needs at work. Journal of Management, 42(5), 1195-1229. https://doi. org/10.1177/0149206316632058.

Van Ruysseveldt, J., Verboon, P., \& Smulders, P. (2011). Job resources and emotional exhaustion: The mediating role of learning opportunities. Work \& Stress, 25(3), 205-223. https://doi.org/10.1080/ 02678373.2011.613223.

Watson, D., Tregaskis, O., Gedikli, C., Vaughn, O., \& Semkina, A. (2018). Well-being through learning: A systematic review of learning interventions in the workplace and their impact on well-being. European Journal of Work and Organizational Psychology, 27(2), 247-268. https://doi.org/10. 1080/1359432X.2018.1435529.

Weiss, D. J., Dawis, R. V., \& England, G. W. (1967). Manual for the Minnesota Satisfaction Questionnaire. Minnesota Studies in Vocational Rehabilitation, 22, 12.

Publisher's Note Springer Nature remains neutral with regard to jurisdictional claims in published maps and institutional affiliations.

M.A. Ilmari Puhakka is a PhD student in the Tampere University, Finland. His research interests include workplace learning and well-being at work.

Dr. Petri Nokelainen is a Full Professor of Engineering Pedagogy in the Tampere University, Finland. His 
research interests include development of professional and vocational excellence (self-regulation, competence) and engineering higher education (regulation of learning and active learning methods).

Dr. Laura Pylväs is a Postdoctoral researcher in the University of Helsinki, Finland. Her research interests include professional and vocational expertise, regulation of learning, and workplace learning. 